\title{
Relative role of bed roughness change and bed erosion on peak discharge increase in hyperconcentrated floods
}

\author{
W. Li ${ }^{1}$, Z. B. Wang ${ }^{1}$, D. S. van Maren ${ }^{1}$, H. J. de Vriend ${ }^{1}$, and B. S. Wu ${ }^{2}$ \\ ${ }^{1}$ Faculty of Civil Engineering and Geosciences, Delft University of Technology, Delft, the Netherlands \\ ${ }^{2}$ State Key Laboratory of Hydroscience and Engineering, Tsinghua University, Beijing, China \\ Correspondence to: W. Li (w.li@tudelft.nl) \\ Received: 14 October 2013 - Revised: 17 January 2014 - Accepted: 14 February 2014 - Published: 1 April 2014
}

\begin{abstract}
River floods are usually featured by a downstream flattening discharge peak whereas a downstream increasing discharge peak is observed at a rate exceeding the tributary discharge during highly silt-laden floods (hyperconcentrated floods) in China's Yellow River. It entails a great challenge in the downstream flood defence and the underlying mechanisms need to be unravelled. Previous study on this issue only focuses on one possible mechanism, while the present work aims to reveal the relative importance of bed roughness change and bed erosion in the hyperconcentrated flood. Using a newly developed fully coupled morphodynamic model, we have conducted a numerical study for the 2004 hyperconcentrated flood in the Xiaolangdi-Jiahetan reach of the Lower Yellow River. In order to focus on the physical mechanism and to reduce uncertainty from low-resolution topography data, the numerical modeling was carried out in a schematized 1-D channel of constant width. The basic understanding that bed roughness decreases with concentration at moderate concentrations (e.g. several $10 \mathrm{~s}$ to $100 \mathrm{~s} \mathrm{~g} \mathrm{~L}^{-1}$ ) was incorporated by a simple power-law relation between Manning roughness coefficient and sediment concentration. The feedback between the bed deformation and the turbid flow, however, was fully accounted for, in the constituting equations as well as in the numerical solutions. The model successfully reproduced the downstream flood peak increase for the 2004 flood when considering the hyperconcentration-induced bed roughness reduction. As the hyperconcentration lags shortly behind the flood peak, later parts of the flood wave may experience less friction and overtake the wave front, leading to the discharge increase. In comparison, bed erosion is much less important to the discharge increase, at least for hyperconcentrated flood of moderate sediment concentration.
\end{abstract}

\section{Introduction}

The Yellow River, the second longest river in China, is famous for the high sediment load in its middle and lower reaches. However, dam construction, water-soil conservation and water diversions for irrigation and other purposes (in addition to climate change) have altered the flow regime and sediment load considerably (Wu et al., 2008a). At the Huayuankou hydrological station where the discharge and sediment load represent those entering the lower reach, the average annual runoff and suspended sediment load were $48.6 \times 10^{9} \mathrm{~m}^{3}$ and $1.56 \times 10^{9}$ tonnes respectively, prior to the construction of the Sanmenxia dam in 1960 (Wu et al., 2008a). Yet in the 1990s, they reduced dramatically to $25.7 \times 10^{9} \mathrm{~m}^{3}$ and $0.7 \times 10^{9}$ tonnes respectively. After the construction of the Xiaolangdi Reservoir (in October 1999), the reduction continued, leading to $20.8 \times 10^{9} \mathrm{~m}^{3}$ and $0.13 \times 10^{9}$ tonnes for the average annual runoff and suspended sediment load respectively in the 2000s.

As a result, the hyperconcentrated flood, which is defined as a water-sediment mixture with sediment concentrations higher than $100-200 \mathrm{~kg} \mathrm{~m}^{-3}$ typically in the Yellow River (Wan and Wang, 1994; He et al., 2012), exhibits obviously different behaviors in different periods, among which the phenomenon of downstream peak discharge increase is the focus of this paper. Before 2000, a downstream increasing peak discharge was occasionally observed during a hyperconcentrated flood that inundated floodplains. The increase was relatively small and the maximal increasing rate was $30 \%$. After 2004 when the water-sediment regulation by the Xiaolangdi Reservoir became operational, an increasing peak discharge of the hyperconcentrated flood was frequently observed between the Xiaolangdi and the 
Huayuankou hydrological stations (in the Lower Yellow River), which are approximately $125.8 \mathrm{~km}$ apart. In this period, the average increasing rate is as high as $50 \%$, with floods of moderate concentrations (i.e., 100 to $400 \mathrm{~kg} \mathrm{~m}^{-3}$ ) mostly conveyed inside the main channel. This considerable increase in the peak discharge greatly increases the flood risk in the lower reach, along with the severe sedimentation due to runoff reduction. Therefore, it is of great importance to unravel the mechanisms underlying the peak discharge increase and to find out solutions for mitigating potential damages.

The peak discharge increase may be related to rapid morphological changes, to a modified bed roughness, or to bed erosion related increasing flow volume. In a hyperconcentrated flood with floodplain inundation, the channel morphological change from wide and shallow to narrow and deep may increase the flow velocity, thus probably causing a downstream increasing peak discharge when the flood peak is caught up by the successive flood waves (Wang et al., 2009). It is also suggested that the intensive sediment transport due to strong bed erosion may contribute to a peak discharge increase by increasing the flow volume of the water-sediment mixture (Cao et al., 2006; Qi et al., 2010). In addition, the bed roughness change in high concentration conditions could also be a main factor for the discharge increase. Field observations and laboratory experiments show that the bed roughness decreases with sediment concentration at moderate concentrations (Jiang et al., 2006; Zhu and Hao, 2008). The decreasing roughness may accelerate flow propagation leading to a downstream peak discharge increase. Jiang et al. (2006) numerically reproduced the peak discharge increase of the 2004 hyperconcentrated flood at Huayuankou by considering the effect of sediment concentration on bed roughness. Based on theoretical analysis, $\mathrm{Li}$ (2008) also suggested that the discharge increase should be attributed to a roughness reduction.

So far, there has been no consensus, however, on which mechanism contributes most to the peak discharge increase. Focusing on the floods mostly conveyed inside the main channel, this paper aims to reveal the relative importance of bed roughness change and bed erosion to the peak discharge increase. The 2004 flood in the Xiaolangdi-Jiahetan reach is revisited by a numerical study using a newly developed morphodynamic model (Li et al., 2013). The effect of bed erosion on increasing flow volume is distinguished by two model versions (a fully coupled version and a partially coupled version). A simple power-law relation is used to represent a decreasing roughness with concentration.

\section{Mathematical model}

The numerical study is conducted using a coupled morphodynamic model based on the finite volume method and the 2nd order extension of upwind-biased First Order Centered (UFORCE, see Stecca et al., 2010) scheme. This model is second order accurate in space and time, and validated by a series of dam-break tests (Li et al., 2013). In this paper, only the basic formulations for the 1-D modeling are introduced; see details in Li et al. (2013).

\subsection{Governing equations}

In a 1-D coupled morphodynamic model of non-capacity sediment transport, the governing equations consist of the mass and momentum conservation equations for sedimentladen flow, the mass conservation equation for sediment in motion, and a bed update equation (Cao et al., 2004). For a fully coupled version (the effects of bed deformation and sediment density on the flow are fully considered), the vector form of the governing equations can be written, following the methods of Cao et al. (2004) and Li and Duffy (2011):

$$
\begin{aligned}
& \frac{\partial \boldsymbol{U}}{\partial t}+\frac{\partial \boldsymbol{F}}{\partial x}=\boldsymbol{R} \\
& \boldsymbol{U}=\left[\begin{array}{l}
h \\
h u \\
h c \\
\varphi
\end{array}\right] \\
& \boldsymbol{F}=\left[\begin{array}{l}
h u \\
h u^{2}+0.5 g h^{2} \\
h u c \\
h u c
\end{array}\right] \\
& \boldsymbol{R}=\left[\begin{array}{l}
\frac{E-D}{1-p} \\
g h\left(S_{0}-S_{\mathrm{f}}\right)-\frac{\left(\rho_{\mathrm{s}}-\rho_{\mathrm{w}}\right) g h^{2}}{2 \rho} \frac{\partial c}{\partial x}-\frac{\left(\rho_{0}-\rho\right)(E-D)}{\rho(1-p)} u \\
E-D \\
0
\end{array}\right]
\end{aligned}
$$

where $\boldsymbol{U}=$ vector of conservative variables; $\boldsymbol{F}=$ vector of flux variables; $\boldsymbol{R}=$ vector of source terms for the fully coupled model; $t=$ time; $x=$ horizontal coordinate; $h=$ water depth; $u=$ depth-averaged flow velocity in $x$ direction; $c=$ depth averaged volumetric sediment concentration; $z=$ bed elevation; $E, D=$ sediment entrainment and deposition fluxes respectively; $S_{0}=-\partial z / \partial x=$ bed slope in $x$ direction; $S_{\mathrm{f}}=$ friction slope; $\rho_{\mathrm{s}}=2650 \mathrm{~kg} \mathrm{~m}^{-3}=$ sediment density; $\rho_{\mathrm{w}}=1000 \mathrm{~kg} \mathrm{~m}^{-3}=$ water density; $\rho=\rho_{\mathrm{W}}(1-c)+\rho_{\mathrm{s}} c=$ density of sediment-laden flow; $\rho_{0}=\rho_{\mathrm{w}} p+\rho_{\mathrm{s}}(1-p)=$ density of saturated bed; $p=$ bed porosity; $g=9.8 \mathrm{~m} \mathrm{~s}^{-2}=$ acceleration of gravity; $\varphi=(1-p) z+h c=$ newly-constructed conservative variable. In order to reveal the contribution of bed erosion to the discharge increase, a partially coupled model, which neglects the effect of bed deformation on increasing flow volume (i.e., mass conservation), is also used as a comparison. It differs from the fully coupled version in the source term,

$$
\boldsymbol{R}^{\prime}=\left[\begin{array}{l}
0 \\
g h\left(S_{0}-S_{\mathrm{f}}\right)-\frac{\left(\rho_{\mathrm{s}}-\rho_{\mathrm{w}}\right) g h^{2}}{2 \rho} \frac{\partial c}{\partial x}-\frac{\left(\rho_{\mathrm{s}}-\rho_{\mathrm{w}}\right)(E-D) u}{\rho} \\
E-D \\
0
\end{array}\right]
$$


where $\boldsymbol{R}^{\prime}=$ vector of source terms for the partially coupled model.

\subsection{Empirical relations}

The friction slope is estimated using Manning roughness $n$

$S_{\mathrm{f}}=\frac{n^{2} u^{2}}{h^{4 / 3}}$

Following Cao et al. (2004), the sediment entrainment and deposition are estimated by the adaptation coefficient $\alpha$, as

$E-D=\alpha \omega_{\mathrm{s}}\left(c_{*}-c\right)$

where $\omega_{\mathrm{s}}=$ effective sediment settling velocity $\left(\mathrm{m} \mathrm{s}^{-1}\right) ; c_{*}=$ sediment transport capacity (-); the coefficient $\alpha$ is calculated by an empirical formula that is widely used in the Yellow River (Wang and Xia, 2001),

$\alpha= \begin{cases}0.001 / \omega_{\mathrm{s}}^{0.3}, & c>c_{*} \\ 0.001 / \omega_{\mathrm{s}}^{0.7}, & c \leq c_{*}\end{cases}$

The effective sediment settling velocity is given by Richardson-Zaki formula,

$\omega_{\mathrm{s}}=\omega_{0}\left(1-\frac{c}{1-p}\right)^{5}$

where $\omega_{0}=$ sediment settling velocity in clear and still water, which is computed by Zhang and Xie (1993)'s formula. The sediment transport capacity is estimated by $\mathrm{Wu}$ et al. (2008b),

$c_{*}=\frac{K}{\rho_{\mathrm{s}}}\left(\frac{\rho}{\rho_{\mathrm{s}}-\rho} \frac{u^{3}}{g h \omega_{\mathrm{s}}}\right)^{m}$

where $K=0.4515 ; m=0.7414$.

Based on the previous experimental findings covering sediment concentration lower than $300 \mathrm{~kg} \mathrm{~m}^{-3}$ (Zhu and Hao, 2008), we use a power law relation to estimate the Manning roughness:

$n=n_{\mathrm{r}}\left(1+c_{\mathrm{r}}-c\right)^{\beta}$

where $n_{\mathrm{r}}=$ reference roughness; $c_{\mathrm{r}}=$ reference concentration; $\beta=$ power exponent $(>0)$. The reference roughness and concentration are set to the initial values $\left(n_{0}, c_{0}\right)$ for each numerical case.

\section{Numerical simulations}

\subsection{Numerical cases and model settings}

In the 2004 hyperconcentrated flood, the measured peak discharge was $2690 \mathrm{~m}^{3} \mathrm{~s}^{-1}$ at Xiaolangdi. About $16 \mathrm{~h}$ later, the peak discharge was $3990 \mathrm{~m}^{3} \mathrm{~s}^{-1}$ at Huayuankou. At both stations, the sediment peak (around $350 \mathrm{~kg} \mathrm{~m}^{-3}$ ) arrived later than the flood peak. The tributaries only contribute to a very small discharge $\left(200 \mathrm{~m}^{3} \mathrm{~s}^{-1}\right)$, which are therefore neglected in the present numerical study.

This flood has been numerically investigated in a 1D schematic channel of constant width. The channel is $226.6 \mathrm{~km}$ long and $1000 \mathrm{~m}$ wide with an initial bed slope of $2.55 \times 10^{-4}$, representing the Xiaolangdi-Jiahetan reach of the Lower Yellow River. The Huayuankou hydrological station is almost half way of this reach $(x=125.8 \mathrm{~km})$. Uniform sediment is considered: sediment median diameter $d_{50}=0.02 \mathrm{~mm}$, bed porosity $p=0.45$. At the upstream boundary, the discharge and concentration measured at $\mathrm{Xi}$ aolangdi are prescribed; at the downstream boundary, the stage-discharge relationship at Jiahetan is used. The initial steady-uniform flow condition is assumed: $h_{0}=0.96 \mathrm{~m}$, $u_{0}=0.6688 \mathrm{~m} \mathrm{~s}^{-1}, n_{0}=0.02328$. The initial sediment concentration is assumed at the capacity state as $c_{0}=0.00438$.

Three cases are simulated to investigate the relative role of bed roughness change and bed deformation on peak discharge increase. Using a fully coupled model, Case 1 considers the contribution of bed deformation on the flow volume (Eq. 4) and a varied bed roughness with sediment concentration (Eq. 11). Case 2 also uses a fully coupled model to include the bed deformation contribution while deploying a constant bed roughness. In Case 3, a varied bed roughness is considered while the effect of bed deformation on the flow volume is neglected by using a partially coupled model (Eq. 5).

\subsection{Numerical results and discussions}

\subsubsection{Discharge hydrographs and concentrations}

Figure 1 shows the discharge hydrographs at distinct locations for the three cases. The results of Cases 1 and 3 are obtained by setting the parameter $\beta=3$ in the roughness equation (Eq. 11). When considering a varied roughness with concentration, Cases 1 and 3 compute a downstream increasing peak discharge (see the first flood peak) in the upper reach $(x=0 \mathrm{~km}$ to $x=125.8 \mathrm{~km})$. During the first flood peak, the sediment peak (Fig. 2), which is slightly behind the peak discharge, results in a considerable roughness reduction. Therefore, the later parts of the flood wave may experience less friction and overtake the wave front causing the peak discharge to increase. In the lower reach $(>125.8 \mathrm{~km})$, the peak discharge is still larger than that Xiaolangdi ( $Q=2690 \mathrm{~m}^{3} \mathrm{~s}^{-1}$ at Xiaolangdi) but decreases downstream probably due to a more diffusive roughness effect with distance increase. Qualitatively, the numerical results of Cases 1 and 3 are in line with the observations that peak discharge increase only occurs in the upper reach for the 2004 flood (Jiang et al., 2006).

Moreover, the contribution of bed deformation to the flow volume is trivial for the 2004 flood as the difference between Cases 1 and 3 is small. Only incorporating the bed 

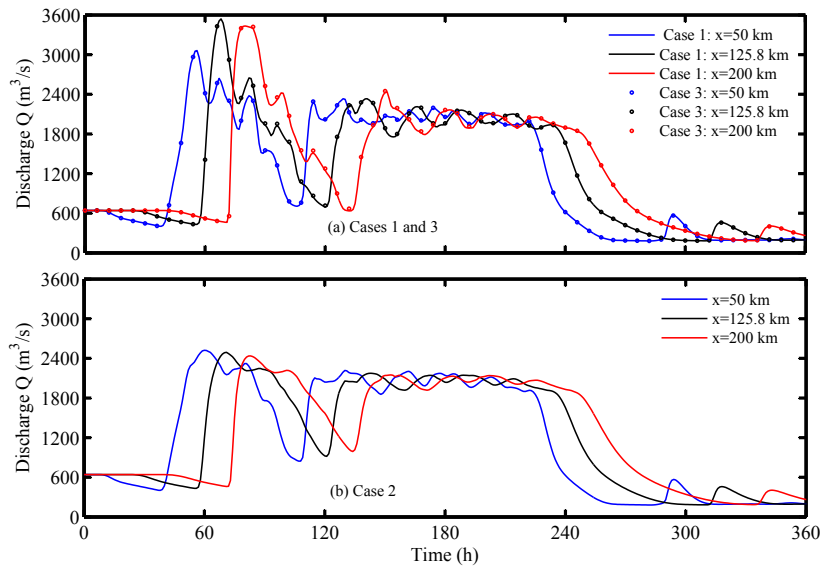

Fig. 1. Discharge hydrographs at distinct locations for (a) Cases 1 and 3, (b) Case 2 .

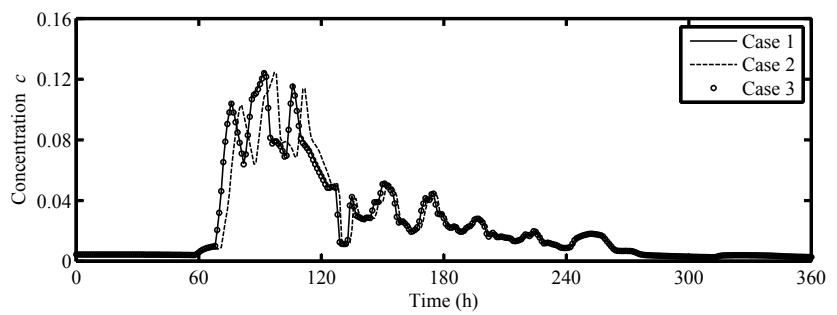

Fig. 2. Sediment concentrations at the Huayuankou station $(x=125.8 \mathrm{~km})$.

deformation effect, Case 2 fails to compute a downstream increasing peak discharge when using a constant bed roughness. Therefore, the effect of bed roughness reduction with concentration is more important to the peak discharge increase than the bed deformation contribution for the 2004 flood.

In addition, there is no peak discharge increase during the second flood peak (after $t=120 \mathrm{~h}$ ) in all the three cases. This is mainly because the sediment concentration is small and changes very slowly (compared to the first flood peak) in this period (Fig. 2), and the effect of roughness reduction cannot be sufficiently strong to induce a discharge increase. Therefore, the difference of the second flood peak between Case 2 and Cases 1-3 is not as significant as the difference of the first flood peak.

\subsubsection{Influence of downstream stage-discharge relationship}

It should be noted that an unjustified downstream boundary condition could cause errors to the computational region. It is unclear whether the outlet stage-discharge relationship drawn from the Jiahetan measurement will affect the findings of downstream peak discharge increase in our 1-D simplified channel. Therefore, an auxiliary computation has been con-

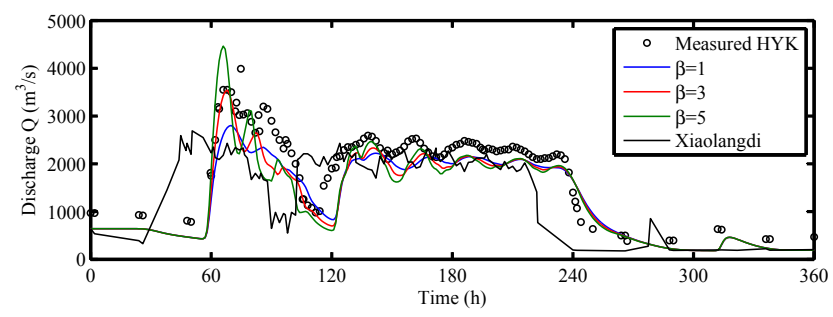

Fig. 3. Computed and measured discharge at Huayuankou, with reference to the discharge at Xiaolandi.

ducted to remove this impact by re-simulating Case 1 in a sufficiently long channel of $800 \mathrm{~km}$ (about the full length of the Lower Yellow River) with a constant water level at the downstream boundary. The results (not shown) illustrate that at the two locations $(x=125.8 \mathrm{~km}$ and $x=226.6 \mathrm{~km})$, the differences of discharge hydrographs are negligible between the short reach $(226.6 \mathrm{~km})$ and the long reach $(800 \mathrm{~km})$, though the computed water level has some small discrepancy at $x=226.6 \mathrm{~km}$ where the downstream boundary of the short reach is located. This implies the stage-discharge relationship based on the Jiahetan measurement is justified for the 1-D simplified short reach and the computed peak discharge increase is not forced by a downstream boundary condition.

\subsubsection{Comparisons of the computation and measurement}

At $x=125.8 \mathrm{~km}$ where the Huayuankou hydrological station is located, the computed results with $\beta=3$ (in Case 1) can well reproduce the measured discharge hydrographs (Fig. 3). For the first flood peak, the computed discharge peak is about $32 \%$ larger than the discharge at Xiaolangdi, which is comparable to the measured data of $48 \%$.

As the present work focuses on the effects of roughness change and bed erosion on the peak discharge increase, sensitivity analysis has been done for the parameters that directly influence these processes. Different values of the parameter $\beta$ (Eq. 11), and the different sediment transport capacity formulae that are suitable for the conditions of the hyperconcentrated flow in the Yellow River, are analyzed. The results show a downstream peak discharge increase can be reproduced when $\beta$ is larger than 1 and the magnitude of discharge peak increases with $\beta$ (Fig. 3). This is valid when different formulae of the sediment transport capacity are used (not shown). In this paper, we present and analyze the computed results by $\beta=3$ because best agreement between the computed and measured discharge peak (also the roughness reduction) is obtained with this value.

\section{Conclusions}

The relative importance of bed roughness reduction and bed erosion-related flow volume increase to the downstream peak 
discharge increase during hyperconcentrated floods is numerically investigated by a newly developed coupled morphodynamic model. The role of bed erosion is highlighted by comparing two model versions: a fully coupled model and a partially coupled model. The effect of bed roughness reduction is considered by a power law relation between the sediment concentration and Manning roughness. The 2004 hyperconcentrated flood with moderate concentrations is modeled in a 1-D schematic Xiaolangdi-Jiahetan reach of the Lower Yellow River.

When considering a decreasing bed roughness with concentration, a downstream peak discharge increase can be computed for the 2004 flood, no matter whether the effect of bed erosion is included or not. While only incorporating the bed erosion effect, the computed peak discharge decreases downstream. Therefore, the effect of bed roughness reduction with concentration is more important than the bed erosion contribution to the peak discharge increase of the 2004 flood. The rapid and considerable roughness reduction immediately behind the flood peak may accelerate the later parts of the flood waves thus leading to the downstream peak discharge increase.

Quantitative uncertainties are embedded in the empirical relations, parameters and simplified topography. Best agreement between the computed and measured results is obtained by setting the parameter $\beta=3$ in the roughness equation. Improvements can be made by using a more realistic topography and advancing the basic understanding of the sediment concentration effects on bed roughness.

Acknowledgements. This research is supported by the China Scholarship Council (2008621194) and the Sino-Dutch collaboration project (08-PSA-E-01).

\section{References}

Cao, Z. X., Pender, G., Wallis, S., and Carling, P.: Computational dam-break hydraulics over erodible sediment bed, J. Hydraul. Eng.-ASCE, 130, 689-703, 2004.

Cao, Z. X., Pender, G., and Carling, P.: Shallow water hydrodynamic models for hyperconcentrated sediment-laden floods over erodible bed, Adv. Water Res., 29, 546-557, 2006.
He, L., Duan, J. G., Wang, G. Q., and Fu, X. D.: Numerical simulation of unsteady hyperconcentrated sediment-laden flow in the Yellow River, J. Hydraul. Eng.-ASCE, 138, 958-969, 2012.

Jiang, E. H., Zhao, L. J., and Wei, Z. L.: Mechanism of flood peak increase along the Lower Yellow River and its verification, J. Hydraul. Eng., 37, 1454-1459, 2006 (in Chinese).

Li, G. Y.: Analysis on mechanism of peak discharge increasing during flood routing in lower reaches of Yellow River, J. Hydraul. Eng., 39, 511-517, 2008 (in Chinese).

Li, S. C. and Duffy, C. J.: Fully coupled approach to modeling shallow water flow, sediment transport, and bed evolution in rivers, Water Resour. Res., 47, W03508, doi:10.1029/2010WR009751, 2011.

Li, W., de Vriend, H. J., Wang, Z., and van Maren, D. S.: Morphological modeling using a fully coupled, total variation diminishing upwind-biased centered scheme, Water Resour. Res., 49, 3547-3565, 2013.

Qi, P., Sun, Z. Y., and Qi, H. H.: Flood discharge and sediment transport potentials of the Lower Yellow River and development of an efficient flood discharge channel, Yellow River Hydraulics Publisher, Zhengzhou, China, 2010 (in Chinese).

Stecca, G., Siviglia, A., and Toro, E .F.: Upwind-biased FORCE schemes with applications to free-surface shallow flows, J. Comput. Phys., 229, 6362-6380, 2010.

Wan, Z. and Wang, Z. Y.: Hyperconcentrated flow. IAHR monograph series, Balkema, Rotterdam, the Netherlands, 1994.

Wang, G. Q. and Xia, J. Q.: Channel widening during the degradation of alluvial rivers, Int. J. Sediment Res., 16, 139-149, 2001.

Wang, Z. Y., Qi, P., and Melching, C. S.: Fluvial hydraulics of hyperconcentrated Floods in Chinese rivers, Earth Surf. Process. Land., 34, 981-993, 2009.

Wu, B. S., Wang, G. Q., Xia, J. Q., Fu, X. D., and Zhang, Y. F.: Response of bankfull discharge to discharge and sediment load in the Lower Yellow River, Geomorphology, 100, 366-376, 2008 a.

Wu, B. S., van Maren, D. S., and Li, L. Y.: Predictability of sediment transport in the Yellow River using selected transport formulas. Int. J. Sediment Res., 23, 283-298, 2008b.

Zhang, R. J. and Xie, J. H.: Sedimentation research in Chinasystematic selections, China Water Power Press, Beijing, 1993.

Zhu, C. J. and Hao, Z. C.: A study on the resistance reduction of flows with hyper-concentration in open channel, in: International Workshop on Education Technology and Training \& 2008 International Workshop on Geoscience and Remote Sensing, Shanghai, China, 141-144, 2008. 